\title{
Incidence of metabolic bone disease in rheumatoid arthritis and osteoarthritis
}

\author{
K. C. NG, P. A. REVELL, M. BEER, B. J. BOUCHER, R. D. COHEN, AND \\ H. L. F. CURREY
}

From the London Hospital, Whitechapel, London E1 1 BB

SUMMARY Bone biopsy specimens from the iliac crest were obtained during surgical operations from 45 patients with rheumatoid arthritis (RA) and 41 with osteoarthritis (OA). Control material was obtained from 20 cases of sudden death due to cardiovascular disease. By both conventional histology and image analysis techniques about a quarter of all patients showed some osteoporosis. This was equally common among the OA and RA patients. It was more common among those with transparent skin and those taking corticosteroids. The only case showing mild osteomalacia suffered from OA. No gross differences were apparent between the groups in relation to plasma biochemical studies, diet, or exposure to sunlight. These results are in striking contrast to the high incidence of osteomalacia in RA reported from the west of England; moreover they do not confirm reports of hypercalcaemia among rheumatoid subjects. We conclude that the differences regarding osteomalacia are due to selection of cases. We find no evidence that osteomalacia is specifically associated with RA.

The disabling deformities of rheumatoid arthritis result from localised bone destruction. Any alteration in the overall quality of bone might be an important factor in determining susceptibility to this erosive process. There are reasons why rheumatoid patients might be more liable to generalised skeletal changes such as osteoporosis or osteomalacia. Apart from the disease process itself, poor diet, reduced physical activity, lack of exposure to sunlight, and drug therapy might all affect the bones. The subject has been reviewed by Kennedy and Lindsay. ${ }^{1}$

Evidence for generalised bone changes in rheumatoid arthritis has come from 2 sources. The first is reports of osteomalacia and/or osteoporosis encountered among rheumatoid patients presenting either with bone pains or spontaneous fractures. ${ }^{2-4}$ The second is the biochemical studies of Kennedy and his colleagues. ${ }^{5}$ These have shown a proportion of rhe umatoid patients to have raised serum levels of calcium and other biochemical changes suggestive of hyperparathyroidism, but with normal circulating levels of parathormone. In addition they found rheumatoid sera to have bone-resorbing activity in vitro. ${ }^{6}$

The most reliable method of diagnosing bone

Accepted for publication 22 June 1983.

Correspondence to Dr K. C. Ng, 20 Pickering Way, Booragoon 6154, Western Australia. changes, particularly osteomalacia, is by histological quantitation of biopsy specimens. ${ }^{7}$ For this reason we have carried out both biochemical studies and iliac crest biopsies on a series of rheumatoid patients coming to operative surgery under general anaesthesia. For comparison patients coming to operation on osteoarthritic joints were also studied. In neither group was there any reason to suspect that the operative procedures might have been made necessary by any generalised bone abnormality. The specimens were assessed both by conventional histological criteria and also by computer-linked image analysis.

\section{Patients and methods}

Patients were selected for entry into the study if they were admitted to the London Hospital for an orthopaedic surgical procedure under general anaesthesia. In all cases the operation was necessary because of either osteoarthritis (OA) or rheumatoid arthritis (RA), the patients in the latter category satisfying the American Rheumatism Association criteria for 'classical' or 'definite' disease. Patients were excluded if they already had a prosthetic hip on the side from which the biopsy would have been taken.

Prior to operation each patient was questioned and examined. In the case of the RA patients an articular 
index of joint tenderness ${ }^{8}$ and anatomical staging of disease $^{9}$ were recorded. A sunlight exposure history was included, and a fasting specimen of blood was obtained between 0800 and $0930 \mathrm{~h}$, without venous congestion, for biochemical determinations. During the period that the patient was anaesthetised an $8 \mathrm{~mm}$ diameter, full-thickness trephine biopsy was obtained from the iliac crest with a Bordier trephine. Signed consent was obtained from each patient after full explanation of the purpose of the study. A subjective assessment of skin transparency (i.e., present or absent) was also made.

\section{BONE ASSESSMENT TECHNIQUES}

Bone biopsy specimens were fixed in $4 \%$ formolsaline and embedded in methyl methacrylate before sectioning at $8 \mu \mathrm{m}$ thickness on a Jung-K microtome. Sections were stained by the von Kossa method and counterstained with van Gieson for the assessment of the volumes of osteoid and mineralised bone. Further sections were stained by the haematoxylin-eosin, thionin, and Gomori's reticulin methods for the general histological examination of the state of the bone. The thionin stained sections were used for measurements of trabecular surface changes by image analysis. All histological and morphometric studies were performed without knowledge of the clinical details.

The routine diagnostic examination was performed by 2 independent histopathologists, each without knowledge of the findings of the other or the quantitative results. There was broad agreement on all biopsies with the exception of 2 , which after discussion were considered to be normal. Other variations between the 2 histologists related only to the degree of change (e.g., mild osteoporosis versus definite osteoporosis). Osteoid volume and trabecular bone volume measurements were made on von Kossa stained sections with the grey-level settings and area mode of a Quantimet 720 image analyser. Surface measurements were performed with the Quantimet by means of a light pen to outline surface features, and the line lengths were then measured. Preliminary investigations indicated that a minimum of $30 \mathrm{~mm}$ length of trabecular surface was needed to reach nominal values for osteoid and resorption surface measurements. Control bone for quantitative study was obtained at post-mortem from the iliac crest of 20 cases of sudden death due to cardiovascular disease. This group comprised 12 males (mean age $59 \cdot 8$ years, range $46-83$ ) and 8 females (mean age $61 \cdot 0$ years, range $47-83$ ).

DIETARY ANALYSIS

A detailed dietary history was obtained from each patient. From this the composition of each diet was calculated by the methods of McCance and Widdowson. ${ }^{10}$

\section{BIOCHEMICAL DETERMINATIONS}

Plasma 25-hydroxyvitamin D (25(OH)D) assays were carried out by the method of Edelstein et al. ${ }^{11}$ using the normal rat kidney-binding protein of Haddad and Chyu. ${ }^{12}$ Serum parathormone (PTH) was assayed by a procedure based on the method of Berson et al. ${ }^{13}$ using the reference standard bovine PTH supplied by the 1st International Reference Group (WHO 71/324), and MRC Antiserum AS/211/32, which has mixed $\mathrm{N}$ - and C-terminal specificity. Plasma calcium, phosphorus, alkaline phosphatase, albumin, urea, and creatinine were measured by standard AutoAnalyzer techniques. Plasma calcium ( $\mathrm{mmol} / \mathrm{l})$ was corrected to a plasma albumin of $46 \mathrm{~g} / \mathrm{l}$ by the following formula:

$$
\begin{gathered}
\mathrm{Ca}(\text { corrected })=\mathrm{Ca} \text { (measured })+0.02(46-\mathrm{A}) . \\
(\mathrm{A}=\text { serum albumin in } \mathrm{g} / \mathrm{l}) .
\end{gathered}
$$

\section{Results}

Of the 90 patients approached 4 refused consent, leaving 86 who were admitted to the study. Forty-five had rheumatoid arthritis, 41 osteoarthritis. Table I lists the characteristics of those from whom adequate specimens were obtained.

We failed to get biopsies from one OA patient and 3 RA patients. These failures occurred early in the study, and we believe that they were not related to the state of the patients' bones. They may have been related to relative inexperience of the person performing the biopsy at the start of the trial, since it has been shown that an inexperienced operator is twice as likely to produce an unsatisfactory biopsy as one who has become familiar with the technique. There were thus 42 specimens from RA and 40 from OA patients available for the study. All of these were assessed by standard histological criteria.

Quantitation by image analysis requires a complete and intact full-thickness specimen, This was available from $29 / 42$ rtheumatoid and $28 / 40$ osteoarthritic patients. The remaining specimens were unsuitable because the trabecular bone had become crushed during the trephine procedure. Clearly this might be a reflection of bone texture and thus introduce selection into which specimens were available for image analysis. In fact examination of these specimens by conventional histology suggests that this was not the case.

Table 2 summarises the histological findings. About one-quarter of all patients were judged to show some degree of osteoporosis, some only mild or borderline in degree. Unexpectedly this was as common among the $\mathrm{OA}$ as in the RA patients and, among 
Table 1 Characteristics of patients on whom histological data were obtained

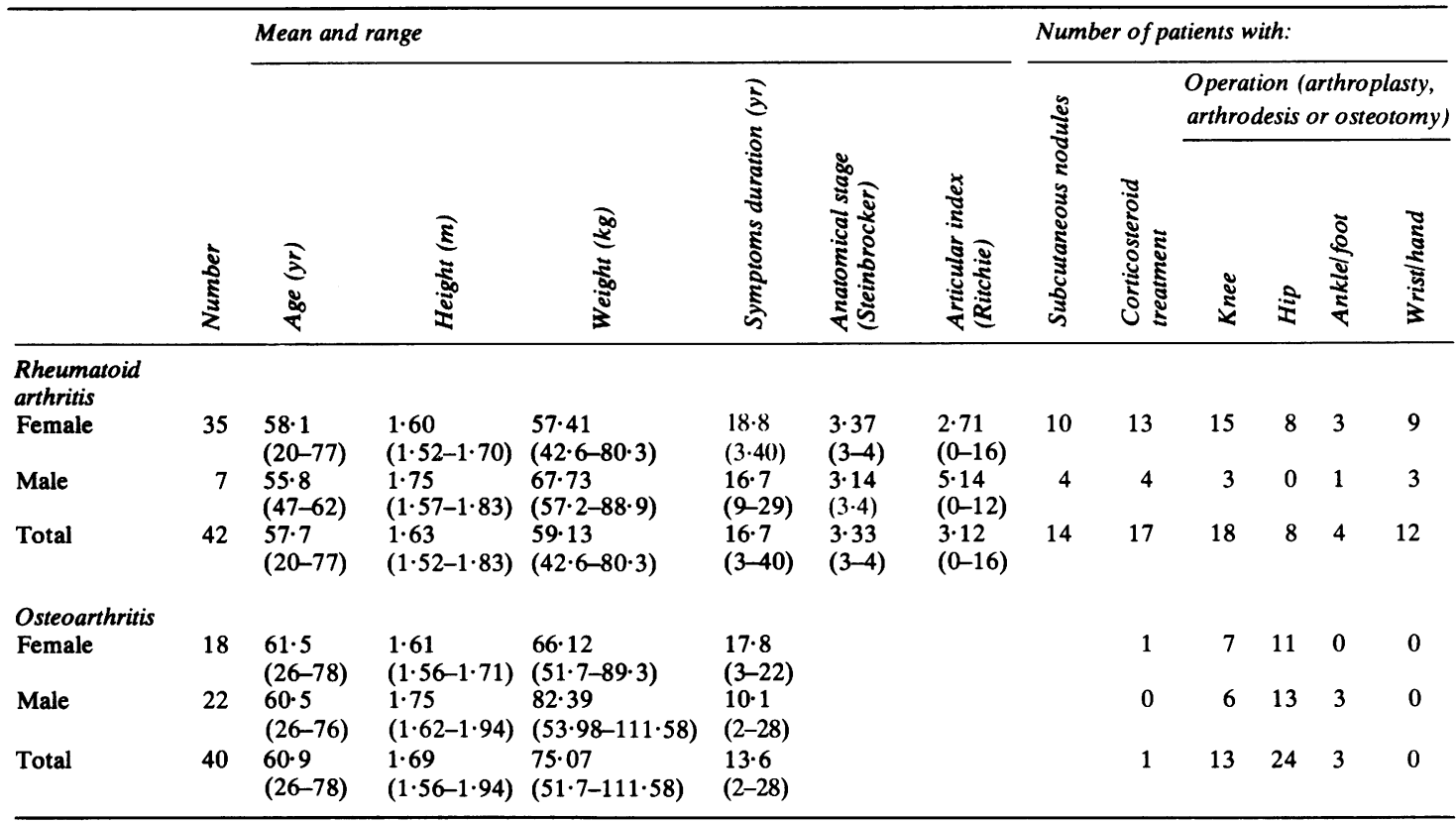

the former, affected men as often as women. Only one patient showed evidence of mild osteomalacia-a man with osteoarthritis.

The histomorphometric data (Figs. 1-4) show a very similar distribution between the $\mathrm{OA}$ and RA patients in regard to trabecular bone volume, osteoid volume, osteoid surface, and resorption surface.
Furthermore, when the morphometric data were analysed by sex and disorder by means of the Mann-Whitney U test, there was no significant difference for any of the morphometric indices between disorders within the same sex. However, trabecular bone volume and resorption surface were significantly lower in RA females than normal females

\begin{tabular}{|c|c|c|c|c|c|c|c|c|c|}
\hline & 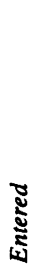 & 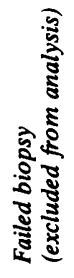 & 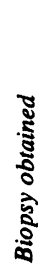 & 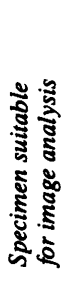 & 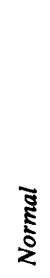 & 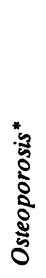 & 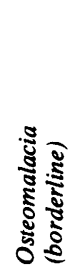 & 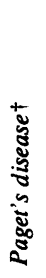 & 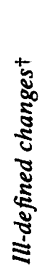 \\
\hline \multicolumn{9}{|c|}{ Rheumatoid arthritis } & \\
\hline \multirow{2}{*}{$\begin{array}{l}\text { Female } \\
\text { Male }\end{array}$} & 7 & 0 & 7 & 6 & 5 & 1 & 0 & 0 & 1 \\
\hline & $\overline{45}$ & $\overline{3}$ & $\overline{42}$ & $\overline{29}$ & $\overline{28}$ & $\overline{12}$ & $\overline{0}$ & $\overline{1}$ & $\overline{1}$ \\
\hline \multicolumn{10}{|c|}{ Osteoarthritis } \\
\hline Female & 19 & 1 & 18 & 10 & 13 & 5 & 0 & 0 & 0 \\
\hline \multirow{2}{*}{ Male } & 22 & 0 & 22 & 18 & 14 & 6 & 1 & 0 & 1 \\
\hline & 41 & $\overline{1}$ & $\overline{40}$ & $\overline{28}$ & $\overline{27}$ & $\overline{11}$ & $\overline{1}$ & $\overline{0}$ & $\overline{1}$ \\
\hline
\end{tabular}

*Including mild and borderline examples.

†No evidence of osteomalacia or osteoporosis. 
Table 3 Association of clinical evidence of increased skin transparency and histological osteoporosis

\begin{tabular}{lll}
\hline Skin transparency & Osteoporosis \\
\cline { 2 - 3 } & Present & Absent \\
\hline +ve & 10 & 12 \\
- ve & 12 & 46 \\
\hline
\end{tabular}

$\chi^{2}$ With Yates's correction $=3 \cdot 743(0 \cdot 10>p>0 \cdot 05)$.

( $p<0.05$ and $p<0.01$ respectively). Trabecular bone volume was significantly lower in OA males than in normal males $(p<0 \cdot 01)$.

Histological osteoporosis was somewhat more common among patients judged to show increased skin transparency (Table 3). Among female RA

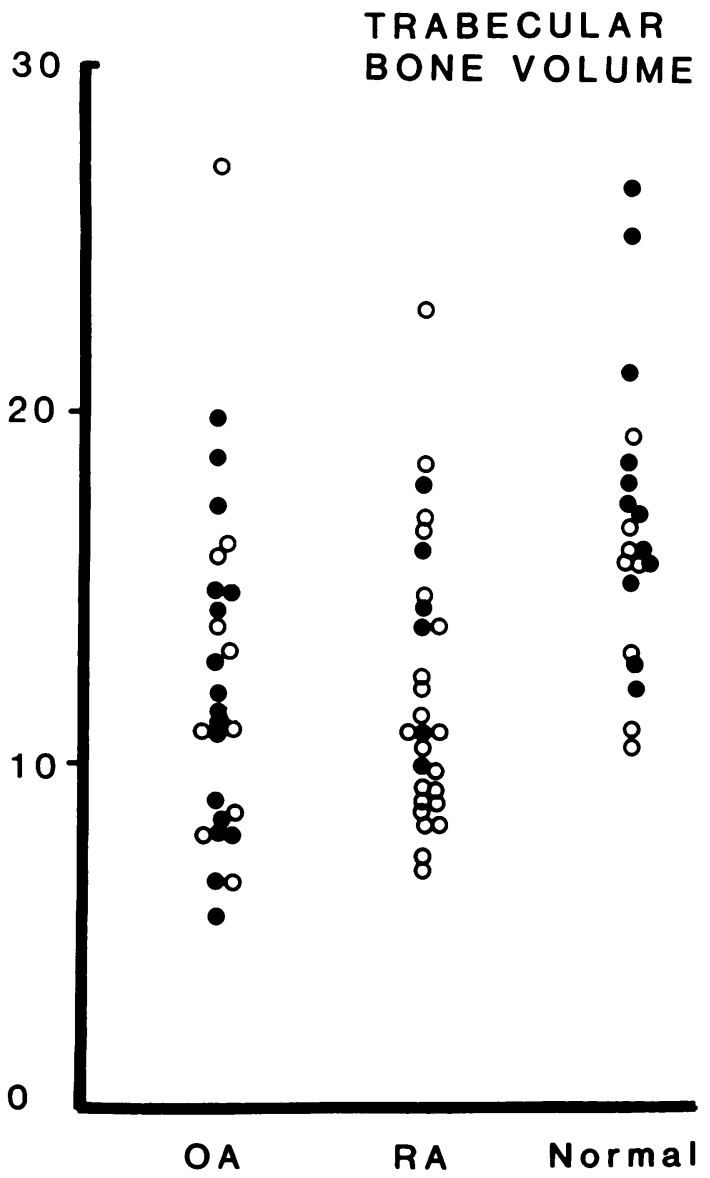

Fig. 1 Trabecular bone volume of iliac crest bone as a percentage of total tissue volume in patients with osteoarthritis $(O A)$, rheumatoid arthritis $(R A)$, and normal subjects. $\bigcirc=$ Males. $O=$ Females. For statistical analysis see Results.

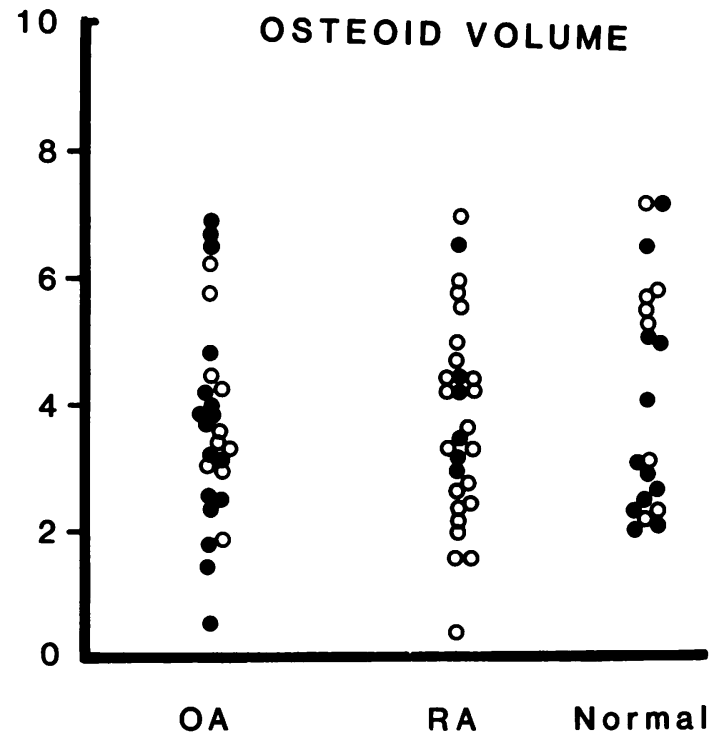

Fig. 2 Osteoid volume of iliac crest bone as a percentage of total trabecular bone in patients with osteoarthritis $(O A)$, rheumatoid arthritis $(R A)$, and normal subjects. $\bullet=$ Males. $\mathrm{O}=$ Females. For statistical analysis see Results.

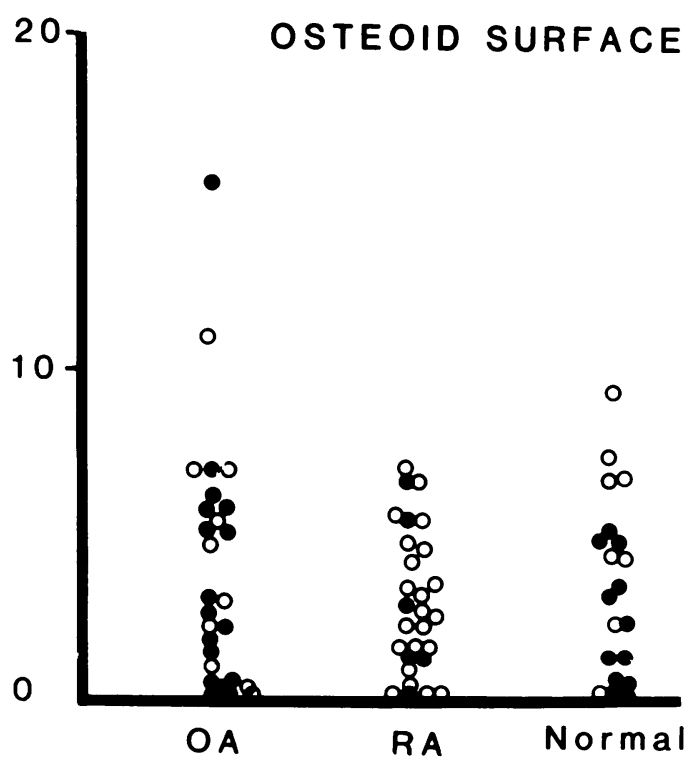

Fig. 3 Osteoid surface expressed as percentage of total trabecular surface in iliac crest bone from patients with osteoarthritis $(O A)$, rheumatoid arthritis $(R A)$, and normal subjects. $\bigcirc=$ Males. $\bigcirc=$ Females. For statistical analysis see Results. 


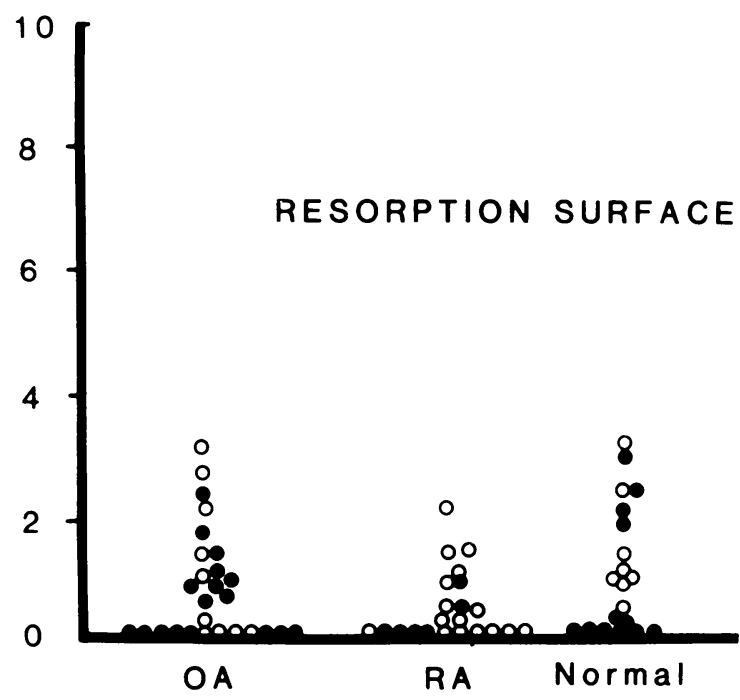

Fig. 4 Resorption surface expressed as percentage of total trabecular surface in iliac crest bone from patients with osteoarthritis $(O A)$, rheumatoid arthritis $(R A)$, and normal subjects. $\mathbf{O}=$ Males. $O=$ Females. For statistical analysis see Results.

patients osteoporosis was more common in those taking corticosteroids (equivalent to at least $2.5 \mathrm{mg}$ prednisolone daily for 1 year within the past 5 years) (Table 4). Male RA patients showed less osteoporosis, but the small numbers do not allow conclusions to be drawn.

Table 5 compares the plasma biochemical values between the 2 groups, broken down by disease and sex. There were no significant differences in corrected plasma calcium and in plasma phosphorus in any of the paired groups. Four RA patients had a corrected plasma calcium greater than $2.6 \mathrm{mmol} / \mathrm{l}$ $(2 \cdot 61,2 \cdot 63,2 \cdot 67$, and $2 \cdot 67 \mathrm{mmol} / \mathrm{l})$ as did $2 \mathrm{OA}$ patients $(2.84$ and $2.75 \mathrm{mmol} / \mathrm{l})$. Chi-squared

Table 4 Association of corticosteroid therapy (equivalent to at least prednisolone $2.5 \mathrm{mg}$ daily for one year within the past 5 years) and histological osteoporosis. Total numbers of female rheumatoid patients (male rheumatoid patients shown in brackets)

\begin{tabular}{lll}
\hline Steroid therapy & \multicolumn{2}{l}{ Osteoporosis } \\
\cline { 2 - 3 } & Present & Absent \\
\hline Yes & $7(0)$ & $6(4)$ \\
No & $1(0)$ & $21(3)$ \\
\hline
\end{tabular}

Fisher's exact test $p<0 \cdot 001$. analysis of the distribution of alkaline phosphatase values showed that the female RA patients tended to have higher plasma alkaline phosphatase than their counterparts with osteoarthritis. There was no difference in the mean or distribution of plasma $25(\mathrm{OH}) \mathrm{D}$. but $5 \mathrm{RA}$ female patients had levels less than $4 \mathrm{ng} / \mathrm{ml}$, as compared with no RA males and one OA male and no OA females. Because of the well known annual variation of plasma $25(\mathrm{OH}) \mathrm{D}$ in normal subjects the timing through the year of sampling in the RA and OA patients was compared. Nearly all samples in both groups were obtained in the months JulyDecember. There was a tendency for the samples in the RA groups to be taken in the autumn, whereas the peak accession of samples in the OA group was in late summer. It is thought unlikely that this difference could substantially alter the interpretation of the results. No significant correlations were found between either plasma $25(\mathrm{OH}) \mathrm{D}$ or PTH and any of the histological indices in either the OA or RA subjects. There was a highly significant reduction in the mean serum parathormone in the RA males compared with the OA males; however, this difference was not apparent in the females and its meaning is uncertain There was no difference in the mean dietary intake of vitamin $\mathrm{D}(\mathrm{OA}, 2 \cdot 7 \mu \mathrm{g} /$ day; RA, $2 \cdot 8 \mu \mathrm{g} /$ day), nor in the distribution of sunlight exposures (classified as negligible, limited, or plentiful) between the $\mathrm{OA}$ and RA patients. Only 4 female RA patients and 2 male and 3 female patients with OA were assessed as having negligible sunlight exposure.

\section{Discussion}

The main finding of this study is a negative one-namely, a virtually complete absence of evidence of osteomalacia in either the OA or RA patients. Though quantitative histology was not obtained on $100 \%$ of each group, there was no histological evidence of osteomalacia in the biopsies which were unsuitable for quantitation. Superficially these results are surprising in view of reports from the west of England of 2 small series and one large group of RA patients ${ }^{2-4}$ in each of which there was a high incidence of osteomalacia. In the last of these papers 54 patients are described with RA and severe osteomalacia attending an orthopaedic department in $\mathrm{Bristol}^{4}$ over a period of $2 \frac{1}{2}$ years. There are, however, several circumstances which may partially or completely explain this gross difference.

Firstly, the selection of the Bristol patients was by virtue of fracture or bone pain. In the present series the patients had been admitted for joint surgery. Our RA subjects were younger (mean age 57.7 years), had overall better exposure to sunlight $(10 \%$ house- 


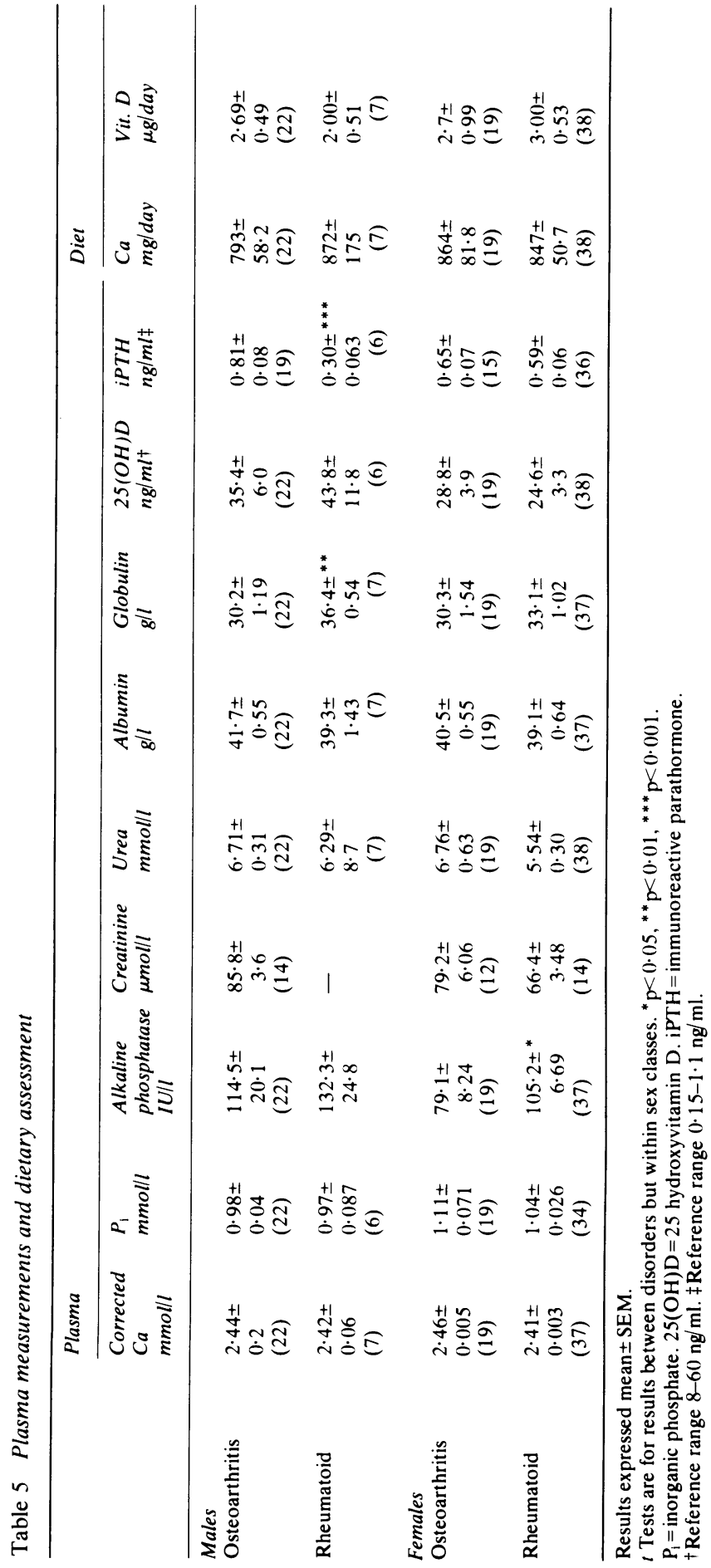


bound versus $50 \%$ ), and received a better dietary vitamin $\mathrm{D}$ intake (mean daily intake $2 \cdot 8 \mu \mathrm{g}$ versus maximum intake of $2.4 \mu \mathrm{g}$ at Bristol). In the present series nearly all plasma $25(\mathrm{OH}) \mathrm{D}$ concentrations were in the normal range. This assay was not available in Bristol. It is likely, but not certain, that these factors account for the very gross differences between the 2 series, and the findings strongly suggest that the osteomalacia syndrome seen in the patients of O'Driscoll and O'Driscoll was little different in aetiology from that prevalent among the elderly population in the UK, in which the principal factors are poor dietary intake of vitamin $\mathrm{D}$, inadequate sunlight exposure, poor intestinal absorption of the vitamin, ${ }^{14-16}$ and inefficient metabolism to the dihydroxylated derivative. There is no evidence that osteomalacia is in any way specifically associated with RA; this does not, however, mean that it should not be carefully sought in those RA patients whose circumstances resemble those in the Bristol series. The patients with OA were selected as a control series of patients who were likely to have similar restriction of access to sunlight. In fact their functional level was somewhat better than that of the RA group, but they were rather older. However, neither their sunlight exposure, dietary intake of vitamin D, nor plasma $25(\mathrm{OH}) \mathrm{D}$ differed significantly from that of the RA group, and it is therefore not surprising that the group was also virtually free of osteomalacia.

It is notable that in a study from the north of England following these observations in the west of England Bird and his colleagues ${ }^{17} 18$ found no biochemical evidence of hypovitaminosis $\mathrm{D}$ among $30 \mathrm{RA}$ patients, nor any difference in plasma levels of 25(OH)D between them and a similar number of matched OA patients. Bird and his colleagues ${ }^{17} 18$ have recently compared plasma 1,25 dihydroxy vitamin D levels in OA and RA patients and found no difference between the groups; furthermore the levels observed were normal for the patients' age group.

The overall prevalence of osteoporosis (including minor degrees) in the present study was $23 / 86$, or $26.7 \%$. This is what might be expected among arthritic patients in this age group. However, osteoporosis was unexpectedly as common among $\mathrm{OA}$ patients as in rheumatoids, and among the former it was equally common in men and in women. Our results certainly provide no support for the impression, mainly anecdotal, that OA and osteoporosis are to some extent mutually exclusive. ${ }^{19}$

Hancock and his colleagues ${ }^{20}$ studied femoral bone mass by photon beam scanning and found it to be reduced in patients with either RA or OA. The main factor in this osteoporosis appeared to be reduced physical activity rather than the arthritis per se, although there may have been an additional contribution from the rheumatoid disease process. Predictably, osteoporosis was more common among our patients taking corticosteroids (Table 4), although in these it is difficult to separate the influence of disease activity. Despite the frequently observed association between corticosteroid treatment and osteoporosis 2 studies of sequential total body calcium measurements failed to show significant mineral loss over periods of 6 and 2-33 months of corticosteroid treatment. ${ }^{21} 22$

Other evidence suggesting a possible alteration in bone metabolism among RA patients comes from the studies of Kennedy and his colleagues. ${ }^{56}$ They found a proportion of subjects with RA to have hypercalcaemia and other biochemical evidence of hyperparathyroidism, but with normal concentrations of serum immunoreactive parathyroid hormone (PTH). In addition they found the sera of patients with RA, especially those with hypercalcaemia, to cause bone resorption when incubated with rat hemicalvaria. In the present series no patients with RA had definite hypercalcaemia, the 2 highest values $(2 \cdot 67 \mathrm{mmol} / \mathrm{l})$ being just within the local reference range for postmenopausal women. Serum PTH levels were within the normal reference range for the particular antibody used locally.

\section{References}

1 Kennedy A C, Lindsay $R$. Bone involvement in rheumatoid arthritis. Clin Rheum Dis 1977; 3: 403-20.

2 Maddison P J, Bacon P A. Vitamin D deficiency, spontaneous fractures, and osteopaenia in rheumatoid arthritis. $\mathrm{Br} \mathrm{Med} J$ 1974 ; iv: 433-5.

3 Bird $\mathrm{H}$ A. Bone biopsy in the investigation of bone pain and fractures. Rheumatol Rehabil 1979; 18: 38-42.

4 O'Driscoll S, O'Driscoll M. Osteomalacia in rheumatoid arthritis. Ann Rheum Dis 1980; 39: 1-6.

5 Kennedy A C, Allam B F, Rooney P J, et al. Hypercalcaemia in rheumatoid arthritis: investigation of its causes and implications. Ann Rheum Dis 1979; 38: 401-12.

6 Kennedy A C, Lindsay R, Buchanan W W, Allam B F. Boneresorbing activity in the sera of patients with rheumatoid arthritis. Clin Sci Mol Med 1976; 51: 205-7.

7 Anonymous. Leading article. Bone biopsy and vitamin D in primary biliary cirrhosis. Lancet 1978; i: 1138 .

8 Ritchie D M, Boyle J A, McInnes J M, et al. Clinical studies with an articular index for the assessment of joint tenderness in patients with rheumatoid arthritis. $Q J \mathrm{~J} \mathrm{Med} \mathrm{1968;} \mathrm{37:} \mathrm{393-406.}$

9 Steinbrocker O, Traeger C H, Batterman E C. Therapeutic criteria in rheumatoid arthritis. JAMA 1949; 140: 659-62.

10 Paul A A, Southgate D A T. McCance and Widdowson's the composition of foods. 4th ed. London: HMSO, 1978.

11 Edelstein S, Charman M, Lawson D E M, Kodicek E. Competitive protein binding assay for 25-hydroxycholecalciferol. Clin Sci Mol Med 1974; 46: 231-40.

12 Haddad J G, Chyu K J. Competitive protein binding assay for 25-hydroxycholecalciferol. J Clin Endocrinol 1971; 33: 992-5.

13 Berson S A, Yalow R S, Aurbach G D, Potts J T. Immunoassay of bovine and human parathyroid hormone. Proc Natl Acad Sci USA 1963; 49: 613-7. 
14 Corless D, Beer M, Boucher B J, Gupta S P, Cohen R D. Vitamin D status in long stay geriatric patients. Lancet 1975; i: 1404-6.

15 Corless D, Gupta S P, Switala S, et al. Response of plasma 25-hydroxy vitamin $D$ to ultraviolet light in long-stay geriatric patients. Lancet 1978; ii: 649-52.

16 Barragry J M, France M W, Corless D, et al. Intestinal cholecalciferol absorption in the elderly and in younger adults. Clin Sci Mol Med 1978; 55: 213-20.

17 Bird H A, Peacock M, Storer J H, Wright V. Comparison of serum 25-OH vitamin D concentrations in rheumatoid arthritis and osteoarthrosis. Br Med J 1980; 280: 1416.
18 Bird H A, Wright V, Hennes V, Theiss E. Comparison of serum 1,25-dihydroxycholecalciferol concentrations in rheumatoid arthritis and osteoarthrosis. Ann Rheum Dis 1982; 41: 257-8.

19 de Séze S, Renier J C, Rakic M. Arthrose vertébrale et ostéoporose. Rev Rhum Mal Osteoartic 1962; 29: 237-43.

20 Hancock D A, Asiedu-Offei S, Atkinson P J, Reed G W, Wright $\mathrm{V}$. Femoral bone mass in patients with rheumatoid arthritis and osteoarthrosis. Rheumatol Rehabil 1978; 17: 65-7.

21 Hosking D J, Chamberlain M J. Osteoporosis and long-term corticosteroid therapy. Br Med J 1973; iii: 125-7.

22 Kennedy A C, Boddy K, Williams E D, et al. Whole body elemental composition during drug treatment of rheumatoid arthritis: a preliminary study. Ann Rheum Dis 1979; 38: 137-40.

\section{Book review}

Textbook of Pediatric Rheumatology. By J.T. Cassidy. Pp. 684. £37.00. John Wiley: New York. 1982.

The data for this book were collected over a 20 -year period, during which time paediatric rheumatology has been developing in a quite remarkable way, with a number of centres providing clinical information, while there has been an increase in knowledge of fundamental biochemical and immunological mechanisms of inflammation.

The first two chapters present a brief discussion of the definition and types of rheumatic disease in children, including an approach to their incidence, prevalence, and classification, as well as the unique paediatric factors that modify rheumatic diseases and interpretation of clinical data. The next chapter is on basic concepts in the pathogenesis of autoimmune disease. As this sets out to be a textbook, it is essential that such a chapter be included, but in some aspects it is patchy and is not quite far-reaching enough for the specialist. The chapter on basic concepts of drug therapy may give rise to a little disquiet in British readers with the very marked emphasis on high dose aspirin. However, the subsequent chapters cover most problems met within paediatric rheumatology, including an excellent review of immunodeficiency and arthritis, one of the editor's particular interests, as well as juvenile rheumatoid arthritis (personally I still quibble with the editor on the term rheumatoid in the child who does not carry rheumatoid factor), the spondyloarthropathies, rarer connective tissue disease, reactive arthritis, infection, as well as differential diagnosis.

The editor's great knowledge and delight in words make the book easy to read. It is beautifully illustrated with clinical photographs, including immunofluorescent studies, and excellent reproduction of radiographs. The charts are clear and the tables easily understood. At times it does tend to be repetitive, and, as with all textbooks, despite the editor's careful choice of both historical and reasonably up-to-date references many are somewhat out of date, while at times the indexing tends to be a little odd. Despite these minor criticisms, this book fills a great need in the field of paediatric rheumatology, supplying a good basic reference book for all the more common disorders encountered.

It has obviously been a labour of love, as well as hard work, in the meticulous way in which the tables and illustrations have been produced. Every hospital that indicates it has a department dealing with paediatric rheumatology should have easy access to this excellent book, while many paediatricians and rheumatologists called on to see an occasional case will find it a wise reference book. 